\title{
Las corporaciones agrarias de Argentina y Brasil ante la crisis de las negociaciones por el ALCA
}

\author{
Julián Kan \\ Centro de Investigaciones sobre Economía y Sociedad en la Argentina Contemporánea, Universidad \\ Nacional de Quilmes, Argentina \\ Centro de Investigaciones en Historia Económica, Social y Relaciones Internacionales, Facultad de \\ Ciencias Económicas, Universidad de Buenos Aires, Argentina \\ Facultad de Filosofía y Letras, Universidad de Buenos Aires, Argentina \\ kanjulian76@yahoo.com.ar
}

Cita sugerida: Kan, J. (2018). Las corporaciones agrarias de Argentina y Brasil ante la crisis de las negociaciones por el ALCA. Mundo Agrario, 19 (40), e080. https://doi.org/10.24215/15155994e080

Recibido: 11 de octubre de 2016 - Aceptado: 1 de diciembre de 2017 - Publicado: 26 de marzo de 2018 
Las corporaciones agrarias de Argentina y Brasil ante la crisis de las negociaciones por el ALCA

Argentinian and Brazilian agrarian corporations facing the crisis of negotations about FTAA

Julián Kan

Centro de Investigaciones sobre Economia y Sociedad en la Argentina Contemporánea, Universidad Nacional de

Quilmes, Argentina

Centro de Investigaciones en Historia Económica, Social

y Relaciones Internacionales, Facultad de Ciencias Económicas, Universidad de Buenos Aires, Argentina Facultad de

Filosofia y Letras, Universidad de Buenos Aires, Argentina

kanjulian76@yahoo.com.ar

\section{RESUMEN:}

El objetivo de este trabajo es analizar las posiciones de las principales corporaciones agrarias de Argentina y Brasil ante las negociaciones por el ALCA entre 2001 y 2005. Para ello se observan publicaciones de las entidades, intervenciones en la prensa y documentación gubernamental sobre las instancias de discusión claves de la iniciativa norteamericana. Las asociaciones aceptaban el proyecto de libre comercio regional, pero manifestaron una serie de objeciones a las propuestas de Estados Unidos que contribuyeron a estancar las negociaciones, en un contexto de reconfiguración política regional y de creciente oposición a las iniciativas de libre comercio.

PaLABRAS CLAVE: Corporaciones agrarias, Argentina y Brasil, ALCA, Negociaciones.

\section{Abstract:}

The aim of this paper in to analyze the positions of the main Argentinian and Brazilian corporations facing the Free Trade Area of the Americas (FTAA) negotiations between 2001 and 2005. For this we observe the entities documents, press intervenntions and governmental documentation about key discussions that have to do with the North American initiative. The associations accepted the regional free trade project, but they expressed some objections to the United States proposals that contributed to pause the negotiations, in a regional political reconfiguration and an increasing opposition to the free trade initiatives context.

KEYWORDS: Agrarian Corporations, Argentina and Brazil, FTAA, Negotiations.

\section{INTRODUCCIÓN}

A poco más de una década del rechazo al Área de Libre Comercio de las Américas (ALCA) impulsada por Estados Unidos, continúa siendo relevante preguntarse por sus causas, sobre todo en el actual contexto de proliferación de acuerdos de liberalización económica y comercial como la Alianza del Pacífico (AP) y el acuerdo MERCOSUR-Unión Europea (UE), a nivel regional, y el Trans-Pacific Partnership (TPP) a nivel global, más allá de su estancamiento desde la llegada de Trump a la Casa Blanca. A comienzos de la década de 2000, la emergencia de los gobiernos denominados progresistas o posneoliberales en la región (Chávez en Venezuela, Kirchner en Argentina y Lula en Brasil) jugó un papel determinante al priorizar la integración sudamericana y cuestionar los alcances de la iniciativa ALCA, en particular, y de los acuerdos inspirados en una lógica comercialista en general. Sin embargo, diversos grupos de la sociedad civil también fueron protagonistas del cuestionamiento, oposición y rechazo a la iniciativa norteamericana. Por ejemplo, los movimientos obreros, sociales y campesinos de varias partes de la región detectaron en proyectos como el ALCA, o en los Tratados de Libre Comercio (TLC), la continuidad de la apertura económica y de un modelo de integración neoliberal con sus consecuencias sobre el desarrollo económico, las condiciones de 
empleo, el nivel del salario y la fragmentación social, entre otros aspectos. Al mismo tiempo, varias fracciones de las clases dominantes locales señalaron objeciones en la cuestión arancelaria, los plazos de implementación y los efectos que traería el ALCA sobre las estructuras productivas. Las observaciones de las corporaciones y asociaciones empresarias del agronegocio en torno a las barreras arancelarias y paraarancelarias y las de la industria sobre la apertura comercial, fueron claves en las negociaciones y contribuyeron a detener el proyecto. Ante una coyuntura política regional adversa para los intereses de Estados Unidos, esta multiplicidad de cuestionamientos terminó de frenar la iniciativa ALCA en la Cumbre de las Américas de Mar del Plata de 2005. A partir de allí los proyectos inspirados en el comercialismo como eje de vinculación perdieron terreno, dando lugar a una integración y cooperación regional más política.

El objetivo de este artículo es analizar y comparar los posicionamientos y acciones de las principales corporaciones agrarias de Argentina: Sociedad Rural Argentina (SRA), Confederaciones Rurales Argentinas (CRA); y de Brasil: Confederación Nacional de la Agricultura (CNA) y Sociedad Rural de Brasil (SRB), en los momentos claves de las negociaciones por el ALCA. Al respecto, se prestará especial atención a la percepción general que las corporaciones tuvieron del proyecto (si lo apoyaron o lo rechazaron), las objeciones y cuestionamientos específicos hacia el mismo, y la relación con los gobiernos ante las instancias determinantes de las negociaciones. Para ello se observará la documentación propia de las asociaciones, los posicionamientos en la prensa escrita y las intervenciones en los encuentros regionales ${ }^{1}$. La hipótesis que orienta el presente trabajo es que el sector agrario de ambos países, a raíz de su gran competitividad a escala internacional, fue propenso en general a la apertura económica y a una mayor conexión con el mercado global, no obstante las condiciones particulares que impuso Estados Unidos en las negociaciones de su proyecto librecambista se tornaron perjudiciales para sus intereses. En este contexto, desarrollaron una serie de observaciones a la iniciativa que, en convergencia con las otras impugnaciones sociales al ALCA, contribuyeron a trabar las negociaciones políticas entre Estados Unidos y los países latinoamericanos.

El artículo se estructura de la siguiente forma. En primer lugar, abordaremos las principales características del proyecto ALCA y su etapa de crisis de las negociaciones. En segundo lugar, analizaremos el acercamiento de las asociaciones empresarias del agro a las negociaciones comerciales y regionales, y su interés en ellas en ambos países. En tercer lugar, indagaremos sobre la conducta de las corporaciones y asociaciones empresarias de ambos países ante el proyecto ALCA.

\section{EL ALCA: OBJETIVOS, DESARROLLO Y CRISIS DE LAS NEGOCIACIONES}

Desde la década del ochenta, en un contexto de restructuración capitalista mundial y de aplicación de políticas neoliberales en América Latina, proliferaron intentos de acuerdos regionales que potenciaban una vinculación estrictamente comercial entre países dispares económicamente y, en algunos casos, también lejanos en el territorio. Por un lado, encontramos los acuerdos orientados exclusivamente en la idea del libre comercio, como los diversos TLC, principalmente el Tratado de Libre Comercio de América del Norte (TLCAN o NAFTA por sus siglas en inglés), y el fallido ALCA, de alcance hemisférico. En estos acuerdos, los países miembros discutían exclusivamente un incremento del intercambio comercial (donde los aranceles y subsidios fueron un tema central) y de las inversiones, como así también los controvertidos temas de patentes, compras gubernamentales y derecho de propiedad intelectual. Por otro lado, encontramos las iniciativas caracterizadas por la Comisión Económica para América Latina (CEPAL) bajo la concepción del "Regionalismo Abierto", donde podemos ubicar a proyectos como el MERCOSUR y la Comunidad Andina de Naciones (CAN), iniciativas que desarrollaron mayores grados de coordinación económica a través de una política aduanera común para la inserción del bloque en el mercado mundial, mecanismos de solución de controversias y asimetrías y algunas formas de institucionalidad supranacional. Sin embargo, en aquella época estos acuerdos tampoco escaparon a la lógica imperante en el escenario de la integración latinoamericana y 
también tuvieron una esencia económica, pero sobre todo comercial (Gudynas, 2005; Kan, 2015; Rapoport, $2008)^{2}$.

La iniciativa ALCA lanzada por Estados Unidos, aunque inconclusa, fue la expresión más acabada de este modelo de integración económico comercialista enlazado con la reestructuración capitalista global y las reformas neoliberales. Esta estrategia estuvo signada por una reformulación del vínculo de Estados Unidos con la región en un período de cambios y de aplicación de las reformas modeladas por el Consenso de Washington. A través de las negociaciones por el ALCA, Estados Unidos retomó la iniciativa de construir una unión comercial y un ámbito panamericano que tenía más de un siglo de historia de intentos en su haber (Morgenfeld, 2011). Además, persiguió una mayor influencia geopolítica, imponiendo tanto la agenda comercial como la de las reformas que se comenzaron a aplicar. Durante toda esa década, bajo la prédica del libre comercio y la apertura, Estados Unidos desplegó un discurso diplomático que apelaba al multilateralismo (con una aparente neutralidad e igualdad de condiciones entre todos los países) para imponer solapadamente sus intereses económicos en las negociaciones por el ALCA y lograr una gravitación geopolítica que encontraba respuesta en varios países, como Argentina, con las llamadas “relaciones carnales”. Aunque la misma CEPAL señalaba las diferencias entre el "Regionalismo Abierto" y el libre comercio a secas, que se manifestaban en la orientación de los bloques subregionales explicada anteriormente, los mismos países que construían esos bloques adherían también al ALCA y, a su vez, mantenían una cercanía a Washington nunca vista anteriormente. A comienzos de la década de 2000, Estados Unidos alentó la firma de TLC con algunos países o subregiones específicas y, al mismo tiempo, continuó reuniendo a todos los países de la región bajo la órbita de las discusiones por el ALCA en las Cumbres de las Américas. Con el inicio de la crisis de las negociaciones del ALCA a partir de 2003 y, sobre todo, con el rechazo de 2005, comenzó a privilegiar la estrategia de cerrar acuerdos pequeños o bilaterales, como los lanzados para Colombia, Centroamérica, Chile y Perú, pero perdió la posibilidad de cohesionar a toda la región en una instancia hemisférica.

Como objetivo principal, el ALCA proyectaba un acuerdo continental que abarcaría desde Alaska hasta Tierra del Fuego. Presentado por Georg Bush (padre) en la conferencia "Iniciativa para las Américas" a mediados de 1990, fue lanzado definitivamente por Bill Clinton en 1994 mediante la Primera Cumbre de las Américas en la ciudad de Miami, con la asistencia y aprobación de todos los países americanos, con la excepción de Cuba que no fue invitada a participar. El propósito era crear un área o zona hemisférica de libre comercio mediante la eliminación de barreras comerciales y arancelarias para la circulación de mercancías. Se proyectaba un mercado de 800 millones de personas con un producto bruto de trece billones de dólares, siendo el principal aporte Estados Unidos con nueve. Pero el acuerdo resultaba dudoso, pues no se trataba sólo de remover las barreras comerciales, sino que incluía cuestiones como la protección de las inversiones extranjeras, un fortalecimiento de los derechos de propiedad por encima de lo recomendado por el Acuerdo General sobre Comercio y Aranceles (GATT por sus siglas en inglés), y luego la OMC, o la obligación de llamar a licitación internacional para las compras gubernamentales.

Como analizaron Estay y Sánchez (2005), Katz (2006) y Morgenfeld (2006), el ALCA fue impulsado por las grandes corporaciones económicas (localizadas principalmente en Estados Unidos) para expandir sus fronteras productivas y comerciales, eliminando instrumentos habituales de los Estados nacionales para proteger a sus firmas o para modelar estrategias de desarrollo. Producto del grado y desarrollo de la capacidad productiva, presionaron por trascender las fronteras nacionales intentando crear un mercado común en todo el continente, con una supremacía que se volvería perjudicial para las industrias locales de los países latinoamericanos. Las palabras del propio Collin Powell, ex secretario de Estado norteamericano, años después de su lanzamiento, evidenciaron el objetivo: "Nuestro objetivo con el ALCA es garantizar a las empresas estadounidenses el control de un territorio que va del Polo Ártico hasta la Antártica, y el libre acceso, sin ningún obstáculo o dificultad para nuestros productos, servicios, tecnología y capital en todo el continente" (Collin Powell citado en Morgenfeld, 2006). Por ejemplo, en relación a las implicancias del acuerdo, $\operatorname{Katz}$ (2006, p. 16) observó que: "El ALCA pretendía brindar a esas empresas la seguridad de amplias 
ganancias por sus inversiones. El convenio incluye controvertidos pagos de patentes, nuevas retribuciones por servicios y ciertos privilegios en futuras privatizaciones".

Las Cumbres de las Américas fueron las reuniones presidenciales donde se discutían los plazos y condiciones del acuerdo, aunque las negociaciones más pormenorizadas tuvieron lugar en las reuniones ministeriales o minicumbres. Desde la tercera Cumbre de las Américas de Quebec, en 2001, las negociaciones comenzaron a trabarse. Si bien Estados Unidos pregonaba el libre comercio y para ello exigía la rebaja arancelaria de los países de la región, no garantizaba la entrada de productos latinos a su país, sobre todo en el área de la agricultura, ya que continuaba manteniendo los subsidios internos a sus productores, denominados paraarancelarios. Por lo tanto, las negociaciones se fueron estancando y los plazos y formas del ALCA comenzaron a rediscutirse. Al mismo tiempo, se inició una creciente protesta social contra el modelo de integración comercialista asociado a las reformas neoliberales, en paralelo a las protestas contra el libre comercio en el marco de la OMC, donde la movilización callejera contra el ALCA en varios países de la región tomó un lugar destacado (Kan y Pascual, 2011; Seoane y Taddei, 2003). Por esos años, a raíz de las luchas sociales contra esas políticas, comenzó a ponerse en crisis la gobernabilidad neoliberal y aparecieron gobiernos que también cuestionaron este modelo de integración económico comercial.

En ese contexto, entre 2003 y 2005 una serie de hechos destacados en torno a la política regional e internacional señalaron un momento de cambios en las discusiones sobre el ALCA y el conjunto de la integración latinoamericana. Nos referimos a los fracasos de la reunión de la Ronda Doha de Cancún de la OMC (septiembre 2003) y sus efectos sobre las discusiones por el ALCA; las reuniones ministeriales de cancilleres y secretarios de Comercio de Miami (noviembre 2003) y Puebla (febrero 2004) para avanzar en los borradores del ALCA; el "Consenso de Buenos Aires" entre Lula y Kirchner (noviembre 2003 y marzo 2004); el fracaso de la extraordinaria Cumbre de las Américas de Monterrey (enero 2004); la crisis en las negociaciones entre el MERCOSUR y la Unión Europea (UE) (2004); y las tensiones en la Cumbre Iberoamericana (octubre 2005). En torno a estos acontecimientos comenzó a reconfigurarse la integración latinoamericana en general y la del Cono Sur en particular. La Cumbre de las Américas de Mar del Plata de 2005 terminó de consolidar esta reconfiguración de los ejes de vinculación entre los países de la región, y entre éstos y Estados Unidos (Kan, 2010).

En el transcurso de este ciclo señalado entraron en tensión Estados Unidos y Venezuela y, al mismo tiempo, se solidificó el bloque MERCOSUR, principalmente la relación entre Argentina y Brasil. Estos últimos, empezaron a sostener una mayor autonomía en los ámbitos regionales y comerciales que la que habían desplegado en torno al Consenso de Washington. Además, los recambios gubernamentales contribuyeron a replantear el escenario de la integración. Primero, con la llegada de Chávez al poder en Venezuela y su paulatina oposición a las políticas norteamericanas y, posteriormente, con el ciclo andino de luchas antineoliberales en Bolivia ("guerra del gas", "guerra del agua” y destitución de Sánchez de Losada), en Ecuador (destitución de Bucaram, luchas contra la dolarización, "rebelión de los forajidos" y destitución de Lucio Gutiérrez) y en Perú (movilizaciones contra Fujimori y las posteriores resistencias al TLC en 2004-2005). Cabe destacar que los cambios de gobiernos de 2003 en Argentina (resultado de la insurrección de diciembre de 2001 que derribó al presidente De la Rua) y en Brasil (la llegada del Partido de los Trabajadores al poder luego de varios intentos) fueron también de suma importancia para la reconfiguración regional.

En este mismo período también hubo una mayor intervención de la sociedad civil sobre la problemática regional. Por un lado, la protesta social contra las políticas neoliberales se extendió a las iniciativas del libre comercio. Nos referimos a las acciones coordinadas por las centrales sindicales de Argentina, Brasil y Uruguay ante las negociaciones por el ALCA, y a las manifestaciones de los movimientos campesinos y sociales en América Central y en varios países andinos contra la firma de los TLC (Kan y Pascual, 2011; Seoane y Taddei, 2003). Por otro lado, la puja entre sectores capitalistas por abrirse a nuevos mercados o por oponerse a una apertura indiscriminada, a través de sus posicionamientos ante las iniciativas de integración como el ALCA, 
donde las negociaciones estaban en curso, o ante el MERCOSUR que venía de una profunda crisis, incidió notablemente sobre los cambios políticos de la región (Kan, 2015).

A continuación repasaremos el estado de las negociaciones comerciales y regionales en el período en cuestión y cómo afectaron a las del ALCA. 2003 fue un año clave ya que se realizaron las reuniones de la Ronda Doha de Cancún del mes de septiembre, y de la minicumbre o reunión ministerial de Miami del ALCA del mes de noviembre. En dichos encuentros las negociaciones adquirieron un curso crítico y, al mismo tiempo, desplegaron sus posturas los negociadores argentinos y brasileños para los dos años posteriores. En la reunión de la OMC demandaron en conjunto con algunos miembros del ex Grupo Cairns, con quienes conformaron "Grupo de los 20, 21 o 22" -según la cantidad de otros integrantes que se iban sumando- una rebaja de los subsidios de Estados Unidos y Europa para sus productores agrícolas, que estableciera mejores términos para la exportación de la producción agropecuaria latina. Sobre ese piso, Argentina, Brasil y otros países discutieron la rebaja de aranceles en otras áreas llamadas "sensibles" para las economías no centrales. Estos reclamos se enlazaban con las demandas de los dos sectores más interesados en esta problemática: el agroexportador y el industrial. El primero de ellos estaba a favor del acceso a nuevos mercados, aunque objetaba la política de subsidios de los países centrales que impedía el libre acceso a los mismos. El segundo grupo, en términos generales, ponía reparos a una mayor competencia externa que ocasionaría la rebaja arancelaria general del comercio de bienes y servicios, pretendiendo que la misma fuera escalonada y contuviera la posibilidad de utilizar mecanismos de protección. No obstante, algunas grandes empresas o grupos económicos apoyaban la apertura debido a la posibilidad de obtener nuevos mercados y tener capacidad para resistir la competencia.

En la reunión ministerial de Miami del mes de noviembre se desplegaron en torno al ALCA varias cuestiones críticas, ya manifestadas en la Cumbre de Quebec de 2001, y similares a las que se discutieron previamente en septiembre en la reunión de la OMC en Cancún. No se esbozó en Miami un rechazo total a la iniciativa norteamericana, pero sí una visión diferente de la forma y los tiempos para implementar el acuerdo. Esto llevó a los planteos de un "ALCA Light", "A dos niveles" o "A la carta", en detrimento del ALCA que proponía Estados Unidos para 2005. La postura de Argentina y Brasil reflotó la utilización del MERCOSUR como bloque regional para negociar el ALCA. A partir de la reunión de Cancún de la OMC los países del MERCOSUR habían acordado un piso para continuar las negociaciones del ALCA en la posterior reunión de Miami, que consistió en la atadura de las negociaciones arancelarias de un ámbito a otro. Esto contenía el planteo de que, hasta que no se resolvieran en la OMC los temas arancelarios, no se destrabarían en el ALCA. Así, en ese estado de cosas, en la reunión de Miami se firmó un documento común sobre un ALCA menos pretencioso, el conocido "ALCA Light", con la siguiente contrapartida positiva para los dos grupos de países. Por un lado, para el grupo de Argentina, Brasil y el MERCOSUR, debido a que la discusión por los subsidios resultaba ardua y prolongada en el marco de la OMC, significó una modificación de las pretensiones de Estados Unidos de firmar el ALCA original en 2005. Por el otro, para los Estados Unidos y sus países aliados, ante los impedimentos de negociar un ALCA hemisférico, se establecía la posibilidad de desplegar acuerdos de libre comercio bilaterales o subregionales. De esta forma, en la reunión de Miami por el ALCA no se registró el fracaso total de las negociaciones como había ocurrido en la Ronda Doha en Cancún, pero tampoco se avanzó en las negociaciones por el tema de los subsidios, los que quedarían pendientes de discusión en el marco de la OMC con la idea de ir quitándolos escalonadamente. Pero como en la OMC estaban trabadas, la posibilidad de destrabarlas en el ALCA era casi remota a esa altura.

En este escenario, en la siguiente reunión ministerial realizada de Puebla, en febrero de 2004, no se produjo ningún avance en las negociaciones. El objetivo de la reunión era discutir el cronograma definitivo para el resto de las reuniones que se mantendría durante 2004 y 2005, donde debería cerrarse el acuerdo y el contenido del ALCA definitivo. Entre otros temas, se abordarían el acceso a mercados, agricultura, inversión, servicios, compras del sector público, propiedad intelectual, política de competencias, subsidios, antidumping y derechos compensatorios, así como solución de controversias. Las partes intentaron acercar 
posiciones sobre el tema de los subsidios y aranceles, pero los resultados fueron otros. Los viceministros de los países americanos, aunque pretendieron avanzar en las negociaciones, no pudieron sortear las tensiones políticas ocurridas en el medio de ambas reuniones ministeriales en la extraordinaria Cumbre Presidencial de Monterrey, convocada de urgencia por Estados Unidos en el mes de enero de $2004^{3}$. Sin ningún piso de acuerdos, la reunión de Puebla fue un fracaso.

Las reuniones posteriores convocadas para abril de ese año no se sustanciaron. En estas condiciones de desacuerdo se llegó, en noviembre de 2005, a la Cumbre de las Américas de Mar del Plata, donde las negociaciones por el ALCA tuvieron su estancamiento definitivo y el proyecto de libre comercio norteamericano quedó detenido.

\section{LAS CORPORACIONES Y ASOCIACIONES EMPRESARIAS DEL AGRO ANTE LAS NEGOCIACIONES REGIONALES Y COMERCIALES}

Desde la década de 1980 en adelante, a partir de la proliferación de bloques zonales y regionales y del proceso de liberalización comercial global, las asociaciones empresarias del agro otorgaron una mayor importancia a las negociaciones internacionales y sus posibles efectos sobre el sector, ya sean positivos o negativos. Sobre todo en países con un fuerte perfil agroexportador como son Argentina y Brasil. Esto implicó que la agendas de las entidades asociativas incorporasen la cuestión de la ampliación de nuevos mercados, la desgravación arancelaria y las trabas paraarancelarias al comercio agrícola, temas de discusión de las diferentes negociaciones comerciales y regionales y globales. Como analizaron Botto y Tussie (2003), en varios países de la región el ALCA generó fijación de posición, o al menos opinión, en documentos e intervenciones específicas sobre el tema, la formación de agrupamientos intercorporativos para ejercer lobby o participar de instancias no gubernamentales de discusión y, además, una mayor interacción con los negociadores gubernamentales en los momentos claves de las negociaciones.

En el caso de Brasil, el interés de las asociaciones y corporaciones empresarias sobre los proyectos regionales y la necesidad de participar e influir en las negociaciones correspondientes fueron en aumento desde ese tiempo. Por ejemplo, en la Ronda Uruguay del GATT, a fines de los ochenta y comienzos de los noventa, la acción diplomática brasileña fue acompañada por sectores representativos de la agroindustria interesados en la liberalización agrícola, aunque sin una participación decisiva del empresariado en la formulación de las políticas negociadoras (Veiga, 2002). En la primera etapa del MERCOSUR se produjo un paulatino crecimiento de la participación empresarial, que podemos apreciar en la constitución de la Asociación de Empresas Brasileñas para la integración en el MERCOSUR (ADEBIM) en 1991, integrada por capitales locales y extranjeros, entidades de representación corporativa y las principales empresas estatales. Esta tradición de participación desarrolló mecanismos domésticos de consulta y negociación que condujeron a una rutina de comunicación entre gobierno y empresarios caracterizada por cierta regularidad (Veiga, 2002, p. 13). Por ejemplo, la Confederación Nacional de la Industria (CNI) tuvo una destacada participación en el Foro Consultivo Económico y Social del MERCOSUR (FCES) desde los comienzos de esta instancia, de la misma forma que en el Consejo Industrial del MERCOSUR (CIM).

Sin embargo, las negociaciones en torno al ALCA implicaron una mayor vinculación de las corporaciones empresarias con la iniciativa comercial, que expresaron la preocupación de las diversas fracciones de las clases dominantes locales por las implicancias que el proyecto traería. En el caso de Brasil, la complejidad de las negociaciones impulsó una reorganización del proceso de interacción entre el gobierno, las asociaciones empresarias y las instancias de negociación, profundizando el denominado ejercicio doméstico de consulta. Esta reorganización respondió, por un lado, al contexto de apertura económica y de aplicación de políticas neoliberales en la región durante la década del noventa, que produjo una aceleración de todas las negociaciones regionales comerciales, como las del ALCA, la OMC y el acuerdo MERCOSUR-UE, sobre todo en la segunda mitad de la década. Por otro lado, al creciente énfasis en la apertura económica acontecido 
con las reformas neoliberales en Brasil que, si bien fueron más moderadas que en Argentina, no dejaron de ser una novedad para una economía históricamente proteccionista. Este interés por la apertura económica de parte de los empresarios creció, principalmente, a partir de la promoción a la expansión de las exportaciones que caracterizaron al segundo mandato del presidente Fernando Henrique Cardoso, cuando a fines de 1997 creó la Agencia de Promoción de Exportaciones con el objetivo de duplicar en cinco años las exportaciones de Brasil. En esta dirección, Cardoso también creó la Cámara de Comercio Exterior (CAMEX), vinculada al Ministerio de Desarrollo, Industria y Comercio Exterior, desligada de Itamaraty para encarar negociaciones comerciales. Este sesgo exportador, aunque centrado en cuestiones monetarias y fiscales, fue una de las características del segundo gobierno del otrora destacado sociólogo brasileño. En torno al ALCA, con anterioridad, el gobierno de Cardoso había creado la Secao Nacional de Coordenação de Assuntos Relativos ao ALCA (SENALCA), un órgano colegiado y representativo de los diversos ministerios y entes negociadores de Brasil, que también desarrolló consultas a los sectores no gubernamentales, específicamente para el caso del agro, a la CNA (Junqueira Botelho, 2003).

Desde el punto de vista asociativo y corporativo, este proceso dio como resultado la creación de la Coalizão Empresarial Brasileira (CEB) que, con el objetivo explícito de intervenir en las negociaciones por el ALCA, configuró una organización multisectorial de entidades de cúpula empresarial que integraba a diversas organizaciones de representación gremial, a empresas privadas de capital local y de capital extranjero y a empresas estatales. La CEB expresó, fundamentalmente, posturas de consenso entre las diferentes fracciones del empresariado, tanto entre los sectores interesados en el ALCA como entre los que pondrían reparos. En un documento de 1999, preparado para el III Foro Empresarial de las Américas (FEA), la propia CEB manifestaba que era fruto del "Resultado de un amplio consenso existente en el ámbito del sector empresarial brasileño” (CEB, 1999, p. 3) ${ }^{4}$. Más allá de nuclear a varios sectores, desde el punto de vista sectorial la CEB estaba comandada por las principales corporaciones del agro, como la CNA, y de la industria, como la CNI y, en menor medida, la FIESP.

Para ese empresariado, el riesgo asociado a la competencia externa y la reiterada disposición de los Estados Unidos y algunos de los países latinoamericanos para concluir el ambicioso acuerdo en un corto plazo, demostraban la posibilidad de una efectiva implementación. Tal como afirma Santana (2000), no se había formado una instancia semejante a la CEB antes del ALCA. Producto de los costos y perjuicios que generaría la no movilización empresarial en torno al proceso decisorio del ALCA, se afirmó en el empresariado la idea de organizase para garantizar una participación coordinada de los empresarios brasileños en el proceso de negociaciones, sin la hegemonía del Ministerio de Relaciones Exteriores (Santana, 2000, p. 69).

Los principales posicionamientos del sector agrario y agroindustrial de Brasil, en el período que analizaremos en este artículo, provinieron de la asociación que nuclea a diversos productores con capacidad exportadora, la CNA, quien se expresó en la voz de sus principales dirigentes, en los posicionamientos oficiales de la organización a través de su Revista Gleba, e incluso, a través de la mencionada CEB ${ }^{5}$. En algunas ocasiones, también encontramos posicionamientos de la SRB, que tiene voz y peso propio por agrupar a los productores agrarios de la gran burguesía paulista, principalmente a los del café, pero también a los productores pecuarios y a empresas agroindustriales que tempranamente fueron parte de la interacción entre el capital agrario, el comercio exportador y el sector financiero, que dio lugar a la conformación del pujante sector del agronegocio en esa región. También encontramos pronunciamientos, a partir de 2003, del Centro de Estudios Icone, un think tank creado por la CNA especializado en diversos temas de comercio internacional, financiado no solamente por entidades representativas del agro sino en forma directa por las grandes empresas del agronegocio. El Icone se propuso como objetivo aportar al gobierno información técnica sobre el comercio internacional de bienes agrícolas. Sin embargo, además del aporte técnico que ya existía para determinadas cuestiones sectoriales, el Icone asumió un papel mayor en la canalización de las demandas del sector. Por ejemplo, desarrolló un significativo lobby para determinados segmentos de la agroindustria y fue un canal de expresión y presión del sector, en pos de adquirir mayor participación y 
protagonismo en las negociaciones del ALCA con un perfil cuestionador de la política comercial agrícola del gobierno brasileño.

En Argentina, el acercamiento de las corporaciones empresarias a los proyectos regionales fue más heterogéneo. Por ejemplo, si bien hubo participación de los empresarios en el diseño del MERCOSUR, aquella no generó ni entidades representativas abocadas a ocuparse del MERCOSUR como tema específico, ni una rutina de comunicación e interacción planificada con el gobierno. Durante la primera etapa del bloque, la participación obedeció, como analizaron López y Porta (1995) y Kan (2015), a la necesidad de intervención del gobierno e interacción con las asociaciones para la resolución de determinados conflictos o problemas sectoriales específicos, sobre todo en los comienzos del bloque, donde tuvo lugar la primera etapa del programa de liberalización comercial arancelaria entre Argentina y Brasil.

En el transcurso de los años noventa esta interacción fue decayendo paulatinamente. Si bien las corporaciones y asociaciones empresarias participaron de los foros empresariales organizados por las cumbres o rondas de negociaciones del ALCA, no generaron una instancia similar a la brasileña CEB que representara al conjunto de las corporaciones empresarias. Por un lado, la crisis iniciada en 1999 con la devaluación del Real y profundizada entre 2000 y 2001 por los intentos de sostener la convertibilidad mediante el endeudamiento externo y la vía deflacionaria, generaron tensiones y alineamientos internos pero no exclusivamente sobre el ALCA o los proyectos regionales, sino sobre el conjunto de las políticas económicas (Kan, 2009). Por ejemplo, el quiebre del "Grupo de los ocho", el enfrentamiento entre dos sectores de la Unión Industrial Argentina (UIA) y la formación del Grupo Productivo, que tuvieron lugar en 1999. Además, éstos evidenciaron el momento de fraccionamiento que transitaba la clase dominante a raíz de los efectos de las políticas económicas implementadas durante los años noventa, que se profundizaron a raíz de la recesión iniciada en 1998 y de la crisis ocasionada por la modificación cambiaria de Brasil de enero de 1999. Por esos años tampoco hubo participación coordinada de los empresarios con Cancillería.

En torno a la relación entre el sector agrario y la política regional y comercial ocurrió un acercamiento similar al de Brasil, aunque sin la organización específica sobre el ALCA que hubo en el vecino país. La apertura económica iniciada en 1989 fue acompañada por las corporaciones y asociaciones agrarias por la posibilidad de incrementar las ventas y la eliminación a las retenciones. Hubo una armonía entre la dirigencia societaria y los representantes oficiales argentinos en reuniones decisivas del GATT y de otras instancias de negociaciones arancelarias a nivel regional y global. Los meses de Junio y julio de 1990 fueron meses claves en negociaciones comerciales, donde se mostraban los primeros grados de apertura económica que el gobierno argentino implementaba, apertura que buscada también en las negociaciones arancelarias de la Asociación Latinoamericana de Integración (ALADI), del GATT y en la firma del Acta de Buenos Aires entre Argentina y Brasil como paso previo al MERCOSUR. La SRA fue parte del diseño de esa política comercial; Guillermo Alchouron, su presidente, negociaba en la entidad con Juan Archivaldo Lanús -embajador argentino en Ginebra ante Naciones Unidas y organismos internacionales como el GATT y la Conferencia de Naciones Unidas para el Comercio y Desarrollo (UNCTAD)-, para diseñar la estrategia de negociación ("Solá: en la Ronda del GATT...”, 1990). El por entonces subsecretario de Agricultura, Ganadería y Pesca, Felipe Solá, junto a los presidentes de SRA y de CRA, viajaba a Europa para negociar con sus pares la cuestión de los aranceles y subsidios (“Solá: en la Ronda del GATT...”, 1990). En esa gira, Alchouron y otros dirigentes societarios se reunían con funcionarios de Estados Unidos y de la Comunidad Económica Europea (CEE), con el objetivo de conocer con antelación sus posturas a llevar a las reuniones de la Ronda del GATT de unos meses después en Ginebra para discutir aranceles. Las dos principales entidades corporativas, SRA y CRA, emitían el siguiente comunicado, registrado en los diarios:

Reconocemos la gestión que llevan adelante el grupo de negociadores oficiales de la República Argentina no sólo en el Grupo Cairns, sino en toda la negociación que se lleva adelante en la Rueda del GATT. Nuestro apoyo radica en las coincidencias que existen en el tratamiento que se ha adoptado para llevar adelante una liberalización racional de los mercados agropecuarios internacionales (“Solá: en la Ronda del GATT...”, 1990) 
Este apoyo al programa de reformas y apertura económica, sobre todo por parte de los productores y exportadores nucleados en la SRA, obedeció a la posibilidad de obtener un incremento en su capacidad exportadora, una tecnología a un mejor precio y, además, obedeció a la cuestión ideológica, manifestada en un histórico ideario de que una economía de libre mercado solucionaría problemas del sector y de toda de la Argentina. Como sostuvo Lattuada (2006), si bien el tipo de cambio sostenido por la convertibilidad generó algunos inconvenientes en el sector, el apoyo al gobierno de Menem y al programa de reformas neoliberales $\mathrm{y}$ apertura fue incondicional durante casi todo su mandato.

Las negociaciones comerciales, sobre todo las del ALCA, se aceleraron en la segunda parte de la década, momento que coincidió con el comienzo de la recesión, el atraso cambiario y la crisis más generalizada de la convertibilidad. Así, la relación entre el gobierno y los empresarios del agro tuvo algunos altibajos, en comparación al sólido apoyo de los primeros años en el marco de un consenso más general sobre el programa de reformas y apertura económica. En el último año del gobierno de Menem, SRA y CRA, en conjunto con la Federación Agraria Argentina (FAA) y CONINAGRO, anunciaban por primera vez en la década un lock out patronal, producto de los efectos regresivos sobre el sector de la reforma tributaria aprobada a fines de 1998 y de la caída sostenida de la rentabilidad a raíz del tipo de cambio, profundizada con la devaluación del Real en enero de 1999 (Kan, 2009; Lattuada, 2006; Salvia, 2014). En ese contexto, el gobierno, y tanto la Cancillería como el ministerio de Economía, desoían los reclamos de los empresarios industriales ante la devaluación de Brasil y la ineficacia del MERCOSUR y, a su vez, alentaban las negociaciones por el ALCA. Durante el gobierno de la Alianza, la política exterior y regional de la Cancillería fue contradictoria con la del ministerio de Economía, sobre todo en torno a la relación con Estados Unidos, Brasil y las negociaciones por el ALCA. Esto profundizó la falta, por un lado, de una política regional clara por parte del gobierno y, por otro, de un diálogo sostenido entre los empresarios y el gobierno. Luego de 2003, en un período de aceleración de las negociaciones comerciales, sobre todo las del ALCA, el diálogo entre gobierno y corporaciones empresarias en general, y las agrarias en particular, fue más intenso, a diferencia de lo que se puede imaginar si se lee esa relación desde el escenario dejado en 2008 por la recordada "Resolución $\mathrm{N}^{\circ} 125$ ".

Los principales posicionamientos del sector agrario de Argentina en el período que analizaremos en este artículo provienen básicamente de la SRA y, en varias circunstancias, de la CRA, generalmente ante la Ronda Doha de Cancún y las negociaciones por el ALCA. La postura de incrementar las exportaciones agropecuarias tenía el consenso de todas las entidades, incluso también de la COPAL que actuaba en conjunto con SRA y CRA en algunas negociaciones internacionales.

\section{LAS CORPORACIONES AGRARIAS ANTE EL ALCA}

\subsection{Brasil}

En el trascurso más intenso de las negociaciones por el ALCA, los representantes del agronegocio brasileño manifestaron más de una vez la conveniencia para el sector de un acuerdo de esa naturaleza. Por ejemplo, la CNA puso siempre en primer lugar las ventajas por sobre los perjuicios a la hora de posicionarse sobre el ALCA. Para Antonio Donizeti Beraldo, Jefe del Departamento del Comercio Exterior de la CNA, se trataba de: Una oportunidad de oro (...) las estimaciones muestran el potencial de ganancias para la agricultura brasileña si el ALCA fuera bien negociado. Las exportaciones agrícolas totales de América Latina, según lo previsto, aumentarían un 14,6 \% con la creación del bloque hemisférico ("El ALCA, una oportunidad...", 2002). La Revista Gleba, órgano de la CNA, en su edición de mayo-junio de 2003, anunciaba: "la CNA afirma que el ALCA es visto como una oportunidad para el agronegocio brasileño, porque representa la eliminación o la reducción significativa de las barreras y otras restricciones de acceso a los mercados agrícolas del hemisferio". En esta dirección, el conocido empresario y lobista del agronegocio, Luiz Fernando 
Furlan, manifestaba: "bien negociado, el ALCA puede ser un tesoro para el Brasil" ("Las negociaciones por el ALCA...”, 2002) ${ }^{6}$.

Sin embargo, las tarifas, el acceso a mercados y los subsidios en Estados Unidos a sus productores agrícolas locales, constituyeron los principales reclamos y objeciones de los sectores exportadores agrarios y agroindustriales al proyecto. De todas formas, hicieron más hincapié en el tema de tarifas y acceso a mercados, que sobre los subsidios domésticos distorsivos de Estados Unidos. La estrategia del sector agrario brasileño consistió en que las negociaciones sobre el segundo aspecto no trabaran las del primero y tampoco el curso general de las negociaciones para la instalación del proyecto ALCA, el que aceptaban y consideraban beneficioso.

En 2001, la CNA ya se manifestaba en busca de un acuerdo donde todo pudiera ser negociado:

"Dentro de los componentes fundamentales para llevar a la mesa de negociaciones, están la inmediata eliminación de todos los subsidios a las exportaciones, un programa de desgravación contemplando todas las formas de tarifas y una cobertura plena de productos, sin exclusiones" ("Un acuerdo donde todo pueda negociarse", 2001). Al año siguiente, en septiembre, la entidad presentó un documento para el VII FEA que se titulaba: "Todo el universo tarifario debe ser negociado y desgravado", donde ratificaban esta postura en torno a las tarifas y los subsidios. En la parte final, el documento declaraba: "los subsidios a las exportaciones agrícolas deberán ser completamente eliminados en el comercio intrazonal” (CNA, 2002).

Por ejemplo, en 2001 la CNA había cuestionado el apoyo estatal norteamericano a sus productores locales y los efectos distorsivos sobre el comercio:

Estados Unidos, alega que es una de las economías más abiertas del mundo, con la tarifa media inferior al $5 \%$. Sin embargo, estudios recientes apuntan que, en el universo de más de 10 mil tarifas, Estados Unidos cuenta con 130 posiciones tarifarias encima del $35 \%$. De estas, 100 están en el agronegocio, protegiendo exactamente aquel conjunto de productos de gran relevancia para Brasil, como jugo de naranja, azúcar, alcohol carburante y derivados del cacao. Además de las barreras tarifarias, Brasil afronta también el problema de las barreras sanitarias, que impiden las exportaciones de diversas frutas y legumbres, y de muchos tipos de carnes. (“Los subsidios distorsivos en Estados Unidos...”, 2001)

Posteriormente, en conjunto con sus pares de los países del MERCOSUR, la CNA continuó su crítica a la política norteamericana de subsidios:

La nueva ley agrícola norteamericana, sancionada por el presidente George Bush, el 13 de mayo de 2002, denominada 'U. S. FARM Security and Investment Acto f 2002', inaugura, sin duda, una nueva etapa en el proteccionismo agrícola mundial (...) La CNA, junto a otras entidades representativas del MERCOSUR, que forman las FARM (Federación de Asociaciones Rurales del MERCOSUR) publicaron un documento en mayo de 2002, repudiando la nueva ley agrícola por contradecir el espíritu de la OMC en cuanto a la liberalización del comercio agrícola mundial y por afectar la credibilidad de la postura negociadora norteamericana en varios frentes de negociaciones internacionales. ("La nueva ley agrícola norteamericana...", 2002)

Los reclamos por este tema en Brasil tuvieron un carácter más sectorializado y no se convirtieron en la estrategia para cuestionar el alcance general del ALCA, como sí ocurrió en Argentina. Por ejemplo, un editorial de la revista Gleba manifestaba su preocupación por los subsidios norteamericanos a los productores agrícolas, pero el reclamo lo hacía a partir de una situación sectorial específica como la reclamada por el sector del azúcar productor de etanol. En aquel editorial, la CNA, en vez de plantear un rechazo al ALCA en caso de no existir concesiones, impulsaba la colaboración entre el gobierno y sus cuadros técnicos para elaborar acciones de conjunto y enfrentar la política norteamericana de subsidios. Los representantes del azúcar proponían un acuerdo entre productores y Estado: "las acciones integradas del gobierno y los productores podrán cambiar la perspectiva y la historia del sector del azúcar y el etanol derivado del azúcar, reafirmando su importancia para la economía nacional” (“Editorial”, 2002). Unos meses después, la CNA proponía un segundo acuerdo al ofrecer estudios técnicos a Itamaraty para iniciar una acción contra la política agrícola norteamericana, cuyos costos honorarios en torno de US\$ 400 mil serían asumidos por las asociaciones del sector agrícola (“La CNA e Itamaraty diseñan...”, 2002). 
Sin embargo, a medida que el tema de los subsidios se discutía en la OMC, y en paralelo repercutía en la región trabando las negociaciones por el ALCA, el reclamo por la eliminación pasó a un segundo plano por parte de las corporaciones agrarias brasileñas, quienes intentaron evitar que el tema frustrara las negociaciones generales con Estados Unidos, como finalmente sucedería desde fines de 2003 en adelante. Observamos entonces que unos meses después ratificaban su postura, pero priorizaban el tema tarifario:

La entidad recomienda que las negociaciones agrícolas en el ALCA prioricen la cuestión de las tarifas en el área de acceso a mercados. Ya existen estudios indicando que las mayores ganancias de comercio son provenientes de la completa eliminación de todas las tarifas que inciden en el comercio agrícola regional. Las otras medidas que afectan al comercio, como el apoyo doméstico, los subsidios a las exportaciones y otras de efecto equivalente, tienen efecto apenas marginal en el aumento de las exportaciones a los países latinoamericanos y el Caribe. ("Priorizar el acceso a los mercados", 2003)

Esta estrategia también sería impulsada por la SRB, quien en abril de 2004, cuando las negociaciones ya estaban trabadas por la cuestión de los subsidios norteamericanos a sus productores, manifestaba que: "La polémica por los subsidios es importante pero no decisiva para trabar las negociaciones por el ALCA" ("La SRB y las negociaciones por el ALCA", 2004).

Las posturas del gobierno de Lula generaron tensiones con el agronegocio. El desencuentro crecía en las variadas objeciones de las corporaciones empresarias a las acciones del gobierno en las rondas de negociaciones, donde la actitud de Itamaraty era percibida con reservas. Cuando las negociaciones transitaron el momento más crítico, se hicieron cada vez más evidentes los desacuerdos. La tensión más fuerte entre el gobierno y el sector agrario la podemos apreciar en el tiempo que media entre las negociaciones de la Ronda Doha de Cancún y las del ALCA de Miami:

Cuando se compara las discusiones de Cancún con las del ALCA, se constata que la voluntad política de buscar superación de los problemas no parece ser la misma. La voluntad política es un ingrediente básico en cualquier proceso negociador. Sin ella no hay entendimiento (...). En el caso del ALCA nuestros negociadores adoptaron un comportamiento antagónico, excesivamente defensivo, exagerando en las negociaciones por el ALCA las amenazas y no las amplias oportunidades de nuevos mercados para los diversos sectores de la economía brasileña. ("Falta de voluntad política...”, 2003)

Posteriormente, en la misma revista se cuestionaba al gobierno de Lula por "ideologizar" las negociaciones: "Sería un error ideologizar las negociaciones del ALCA, un ALCA bien negociado representa más comercio, un factor indispensable para el desarrollo a largo plazo de la economía brasileña, el dogmatismo ideológico debe tener fin en esta mesa de negociaciones" ("Falta de voluntad política...", 2003).

En abril de 2004, fracasada la reunión ministerial de Puebla, cuando las negociaciones no tenían fecha de próximo encuentro, Gilman Viana Rodrigues, vicepresidente de Asuntos Internacionales de la CNA, declaró sentir una visión: "No explicitada por el gobierno, de que todo negocio con los Estados Unidos, es ruina para Brasil" ("Los componentes ideológicos en las...", 2004). El presidente de la Asociación Brasileña de Exportadores de Cítricos, Ademerval García, lo expresaba de esta forma: "La negociación está siendo trabada por un componente ideológico. No se trata de una negociación con Estados Unidos desde el punto de vista político, sino de una negociación con el continente desde el punto de vista comercial" ("Los componentes ideológicos en las...”, 2004).

Entre fines de 2003 y comienzos de 2004, el escenario se redireccionó y la única posibilidad de realización en el mediano plazo de alguna forma de ALCA la constituyó el ALCA "Ligth", con plazos más relajados y atando las negociaciones a las de la Ronda Doha. En el período que transcurrió entre las reuniones ministeriales de Miami y de Puebla, se evidenciaron varias de las contradicciones que venían apareciendo. Por un lado, entre el sector agrario del empresariado y el gobierno y, por el otro, al interior del gobierno entre los diferentes ministerios por presión de las corporaciones agrarias; y también, entre el sector agrario y el sector industrial.

En una reunión preparatoria de la cumbre ministerial de noviembre de Miami, que tuvo lugar en Trinidad y Tobago, los negociadores brasileños, en conjunto con los argentinos, insistieron en no abordar ningún 
tema si no se trataba la cuestión de los subsidios agrícolas norteamericanos. Esa postura provocó tensiones entre Estados Unidos, Brasil y Argentina, cuando el gobierno norteamericano acusó al de Lula de querer obstruir las negociaciones del ALCA ("Peleas en el gabinete de Lula", 2003). El ministro de Agricultura, Ganadería y Abastecimiento, Roberto Rodrigues, declaraba: "Sentirse avergonzado por la actuación de la Cancillería en las negociaciones de la semana pasada, en Trinidad Tobago, una de las etapas para la formación del ALCA" ("Peleas en el gabinete de Lula" 2003). Rodrigues, un importante empresario rural de San Pablo -anteriormente presidente de la SRB y de la Asociación Brasileña del Agronegocio (ABAG) - ministro entre 2003 y 2006 del gobierno de Lula, disintió varias veces con el canciller Celso Amorin y hasta con el propio Lula en las negociaciones comerciales y regionales. En esos días, afirmaba que Itamaraty: "Actuó de forma rígida e intransigente" al no haber aceptado abordar todas las áreas en la negociación por el ALCA. Para el ministro esa postura difería con la que la delegación brasileña asumió en las negociaciones de Cancún de la OMC, donde lideró la formación del grupo G-20 de países en desarrollo: "El éxito de Brasil en Cancún fue resultado de una unión de fuerzas del gobierno y la iniciativa privada, liderada por Itamaraty. En cambio, en Trinidad Tobago, los negociadores brasileños se mantuvieron distantes" ("Peleas en el gabinete de Lula" 2003). Por el contrario, el canciller Celso Amorim defendió la actuación de los negociadores brasileños en Trinidad Tobago y, en alusión a lo señalado por Rodrígues, sostuvo que hubo una: "interpretación errada" de lo que sucedió ("Peleas en el gabinete de Lula" 2003).

En este contexto, la CNA manifestó su disconformidad con el resultado de la reunión de Miami, que abrió la posibilidad del "ALCA Light". Al respecto, la corporación agraria señaló:

Se trata de un formato hoy considerado ultrapasado e incapaz de incorporar los flujos dinámicos de bienes, servicios e inversiones, que demandan reglas y disciplinas en diversas áreas. La propuesta del ALCA Light consiguió el hecho inédito de atraer la unanimidad contraria de los países americanos, inclusive de parte del MERCOSUR a la fuerza aglutinadora de la posición. Por ejemplo en México, la propuesta del ALCA Light de Brasil no consiguió obtener apoyo (...) pero dejó a Brasil aislado y al MERCOSUR dividido. (“Falta de voluntad política...", 2003)

Posteriormente, en el contexto de la reunión de Puebla, la CNA indicó: "Sin concesiones no habrá ganancias (...). La falta de disposición en negociar y hacer concesiones en otros temas limita la posibilidad de obtener ganancias en las áreas prioritarias" ("Las negociaciones de Puebla...”, 2004).

Como estrategia, en ningún momento los sectores del agronegocio brasileño acudieron a la necesidad de utilizar el MERCOSUR como herramienta de negociación del ALCA, como sí ocurrió en Argentina, estando aún el bloque regional en crisis desde 1999, profundizada entre 2001 y 2002 por la crisis argentina. Por el contrario, la opinión sobre el bloque regional era predominantemente negativa para el agronegocio brasileño: "el MERCOSUR está en estado invertebrado, en estado gaseoso" ("Un acuerdo donde todo pueda negociarse" 2001). Posteriormente, la CNA propuso que Brasil realizara algunas negociaciones por separado del MERCOSUR "en algunos productos como el azúcar, en el cual el Brasil es hipercompetitivo" (“El lugar de Brasil en las...”, 2003). Al respecto, advertía que: Si Brasil no tiene una posición fuerte en este tema se corre el riesgo que el azúcar y el alcohol de etanol quedaran fuera del ALCA, repitiéndose lo que aconteció en el MERCOSUR, donde el azúcar quedó fuera de la integración. (“El azúcar y los subsidios...”, 2003)

La crítica a otros sectores empresarios, básicamente de la industria, rodeaba también el posicionamiento de los sectores agroexportadores ante el ALCA:

El agronegocio brasileño ciertamente va a perder millones de dólares en exportaciones para nuevos mercados si el Brasil sale del ALCA, además otras pérdidas significativas en otros sectores competitivos de la economía nacional. No se puede cambiar ganancias palpables y concretas de acceso a nuevos mercados en el ALCA, principalmente al mercado norteamericano, por ganancias abstractas en la divulgada preservación de nuestra independencia en torno a la política tecnológica e industrial. (“Falta de voluntad política...”, 2003)

En torno a la reunión de Puebla, la CNA insistió con las concesiones y criticó a los sectores protegidos llamándolos "ineficientes":

El sector agrícola puede verse como el mayor perdedor de este proceso, como es previsible, por cómo el ALCA es defendido por los negociadores oficiales brasileños. Sin concesiones no habrá ganancias. Impedir la apertura de sectores no preparados 
para evitar la competencia parece ser la verdadera prioridad del gobierno. Se sacrifica a los sectores competitivos como el agrícola que quedan excluidos de los beneficios de la integración. Se hace cada vez más evidente el paradigma que banaliza las posiciones negociadoras de Brasil y el MERCOSUR es la protección a los sectores ineficientes, en detrimento de los sectores más abiertos y competitivos. (Revista Gleba, enero-febrero 2004)

A modo de síntesis, con respecto a la percepción general que tuvieron del proyecto no cabe dudas que los empresarios brasileños del agro, a través de sus principales corporaciones y asociaciones, apoyaron la instalación del proyecto ALCA. Básicamente, por los beneficios en la ampliación del comercio que el mismo podía llegar a bridarles como sector con un alto grado de competitividad a escala regional y global. Sin embargo, esbozaron algunas objeciones y cuestionamientos específicos en torno, principalmente, a la falta de avance en una reducción general del cuadro tarifario que incrementara la oferta comercial. En segundo plano, también cuestionaron la existencia de subsidios domésticos e internos a los productores norteamericanos que dificultaban la entrada de productos latinos a aquel mercado, aunque poniéndola en un segundo plano si esto trababa las negociaciones generales. Por último, la percepción de las asociaciones sobre el accionar de la esfera gubernamental en las negociaciones fue negativa, entendiendo que desde la cancillería brasileña, producto de una visión politizada, se perdió la posibilidad de lograr algún tipo de acuerdo que beneficie al sector.

\subsection{Argentina}

Desde fines de 2002, cuando se había anunciado la realización de la reunión de la Ronda Doha de Cancún para septiembre de 2003, varios países y actores políticos y sociales con intereses involucrados en el comercio mundial comenzaron a posicionarse sobre el tema de los aranceles. Como afirmó Morgenfeld (2006), por esos años en Argentina los sectores agroexportadores veían en el ALCA, al igual que en la OMC, la posibilidad de negociar una rebaja de subsidios domésticos por parte de Estados Unidos, cuestión que consideraban clave para avanzar en las negociaciones. La SRA, por ejemplo, pretendía que se llevaran a la mesa de negociaciones todos los temas que impedían el libre comercio de sus productos agrícolas, donde la cuestión de los subsidios distorsivos tomó una relevancia central. Esta entidad venía apoyando las posturas gubernamentales de Argentina en el Grupo Cairns, en conjunto con Brasil y otros países exportadores de otras partes del mundo (todos hacia los países centrales), quienes pugnaban por el fin del proteccionismo agrícola de aquellos, fundamentalmente de Estados Unidos y la Unión Europea (Morgenfeld, 2006, p. 77). Las medidas reclamadas por las corporaciones agrarias argentinas iban en la dirección de bregar por que las potencias dejaran de subvencionar a sus productores agrícolas, permitiendo ingresar libres de subsidios las exportaciones agrarias. Al igual que otras organizaciones empresarias argentinas, la SRA apoyaba la utilización del MERCOSUR -a pesar de su crisis interna y sin reparar tanto en ella como los brasileñoscomo estrategia de negociación del país y mantenía una interacción con funcionarios claves en los momentos relevantes de las negociaciones. También CRA y COPAL lo hacían, aunque con menos aparición pública sobre estos temas.

A comienzos de 2003, la SRA daba a conocer un documento firmado por su presidente Luciano Miguens, que se titulaba "ALCA: sin el agro no hay negociación posible" (SRA, 2003), y apoyaba el ingreso de Argentina en el ALCA pero en determinadas condiciones:

La relación entre el ALCA y el MERCOSUR están llegando a un punto crucial en relación al futuro comercio de bienes y servicios entre ambos bloques. La posición de la Sociedad Rural Argentina al respecto se sustenta en, al igual que en Cancún, llevar a la mesa de negociaciones todos los temas que impiden el libre comercio de productos agrícolas. Los aspectos que entendemos que se deberían abordar son en grandes líneas tres: (1) Acceso a mercados: solicitud de ampliación de cuotas, reducción de aranceles, autorización de ingreso de nuevos productos, etc.; (2) Reducción de ayudas internas: solicitud de mecanismos compensatorios por producto; (3) Eliminación de subsidios a la exportación: compromiso de reducción escalonada del presupuesto para estos fines. (SRA, 2003) 
En el documento se afirmaba el carácter de Argentina como país agroexportador y el potencial impacto sobre las exportaciones agrícolas en caso de firmarse el ALCA. Además, se retomaba una idea clásica de los sectores agroexportadores argentinos, defendida históricamente por la SRA, donde el libre comercio era la llave para erradicar los problemas de la economía argentina. Se impulsaba un modelo de país donde las exportaciones agrarias, potenciadas por un crecimiento del intercambio comercial con Estados Unidos vía ALCA, conllevarían a la eliminación del desempleo:

No se puede desconocer el potencial impacto positivo para las exportaciones de agroalimentos y para el país de lograr avances en los tres temas, teniendo en cuenta que el $60 \%$ de los envíos al exterior de la Argentina corresponden a productos del campo (...). Lácteos, carne ovina y bovina, cítricos, azúcar, maní, miel son algunos de los agroalimentos que podrían verse beneficiados por la liberalización del comercio con el ALCA, lo cual implicaría una sustancial baja del desempleo, ya que todas estas producciones se tratan de actividades que requieren mano de obra intensiva. (SRA, 2003)

Algunos meses más tarde, con Kirchner ya como presidente, la SRA volvía a posicionarse a favor del ALCA y apoyaba la postura del gobierno argentino de utilizar el MERCOSUR como herramienta de cohesión regional para negociar en mejores términos el ingreso al ALCA. En su discurso de apertura de la $117^{\circ}$ Exposición Rural de Palermo, en el marco de varias críticas a las primeras acciones de Kirchner como presidente, Miguens reafirmaba el ingreso al ALCA a través del MERCOSUR, cuestión en la que sí acompañaron al gobierno: "Con referencia al MERCOSUR, dijo que 'apoyamos la acción del Gobierno de respaldar el desarrollo del mercado regional', para que desde ahí se pueda 'negociar en el ALCA”" ("El palco oficial, con un tono de calculada austeridad...”, 2003) ${ }^{7}$.

Unos días más tarde, acercándose la Cumbre de Cancún de la OMC, en la inauguración de la $68^{a}$ Exposición de Ganadería de la Sociedad Rural de Corrientes, el presidente de la entidad solicitaba que:

El agro no sea moneda de cambio en OMC. No debemos confiarnos, tenemos que asegurarnos que el tema agrícola no sea utilizado como históricamente se ha hecho, y debe quedar muy claro: el agro no es una moneda de cambio en las negociaciones internacionales ("Piden que el agro..." 2003).

Al mismo tiempo, le solicitaba al secretario de Comercio y Relaciones Económicas Internacionales, Martín Redrado, que "El tema agrícola sea prioritario en la próxima reunión de Cancún, organizada por la OMC" ("Piden que el agro..." 2003).De esta forma, la dirigencia agropecuaria pedía enlazar la estrategia negociadora en la OMC con la del ALCA.

La postura oficial de Argentina para la Ronda Doha de Cancún expresaba, sin dudas, un entendimiento entre el gobierno argentino y las corporaciones empresarias en relación a la eliminación de subsidios por parte de los países centrales. La comunión entre los empresarios del agro y gobierno comenzaba a agilizarse cuando se acercaba la reunión de Miami del ALCA. El sector agroexportador fue el principal interesado en concretar alguna negociación y públicamente pedía negociar el ALCA si Estados Unidos eliminaba los subsidios internos a sus productores agropecuarios. Al respecto, Luciano Miguens declaraba: "Pensamos que el Mercosur debe pelear para que los Estados Unidos abran su comercio al azúcar, maní, carne y cítricos” ("Los empresarios piden negociar...” 2003). Días más tarde, mediante un comunicado oficial, la SRA reclamaba la incorporación de "Todos los temas que impiden el libre comercio de productos agrícolas a las negociaciones por el ALCA que se desarrollaban en la VII Reunión Ministerial en Miami” (“La cumbre de Miami...” 2003). En este comunicado pedían nuevamente abordar el tema del acceso a los mercados, pero a su vez reclamaban por la reducción de ayudas internas y la eliminación de subsidios a la exportación. Como ya se señaló, la reunión de la $\mathrm{OMC}$ en Cancún tuvo como resultado la traba en las negociaciones comerciales globales, básicamente por la cuestión de los subsidios. El sector agrario argentino entendía como positivo de ello la acción gubernamental de transferir esas condiciones a las negociaciones por el ALCA, donde existía una mayor posibilidad de acuerdo en comparación a la OMC. Sin embargo, como aspecto negativo existía la posibilidad de que no se avanzara en ningún tipo de negociaciones y que las del ALCA también quedaran trabadas de la misma forma que la OMC. Las principales corporaciones agrarias no eran partidarias de 
llegar a esta situación, ya que veían como un mercado más que interesante a los Estados Unidos. En ese estado de situación, el encargado de las negociaciones económicas del gobierno, Martín Redrado, aseguraba desde Miami que la Argentina insistiría para que "Estados Unidos y Canadá eliminen para los países del hemisferio los subsidios a la producción y exportación agrícola y termine con las prácticas que distorsionan el comercio" ("La cumbre de Miami...” 2003). A diferencia de Brasil, el entendimiento entre el sector agrario y el gobierno fue más firme.

Algunas divergencias aparecieron entre SRA y CRA en torno a los beneficios del acuerdo, en ese contexto de negociaciones. Sobre la reunión de Miami y el futuro del acuerdo, opinaba el director del Instituto de Negociaciones Internacionales de la SRA, Raúl Roccatagliata: "El sector agropecuario tiene mucho por ganar. Es ilógico que el agro le diga no al ALCA". Al mismo tiempo, reclamó que Estados Unidos, "competidor en carnes y cereales compense a los países eficientes en su producción por las ayudas internas que planea mantener a sus agricultores" ("La versión light para la liberalización..." 2003). Por otro lado, el por ese entonces presidente de CRA, Benito Legeren, juzgaba al proyecto de la siguiente manera: "Un ALCA que reduzca sólo aranceles puede mejorar las exportaciones, pero resultará un arreglo incompleto." En la misma dirección, con un tono más crítico aún, por el lado de CONINAGRO, Mario Raiteri alertaba de los riesgos: "Los norteamericanos tienen una economía distinta y más desarrollo tecnológico", dejando así planteado el problema de la competencia de Estados Unidos en Brasil, además del posible avance de la maquinaria agrícola y los agroquímicos de la superpotencia ("La versión light para la liberalización...” 2003).

Para el fracasado encuentro de Puebla, el negociador argentino, Martín Redrado, llevó una propuesta cerrada para retomar las negociaciones: Estados Unidos y Canadá deberían aceptar algún desmantelamiento de los significativos subsidios a las exportaciones agrícolas hacia el continente -para las que el gobierno de Bush destinaba 5.000 millones de dólares anuales- y también negociar los subsidios a su producción agrícola para el mercado interno norteamericano. No obstante, la posición de la Argentina intentaba, en pos de lograr un acuerdo, ser más flexible en esto último pero continuar discutiéndolo en el marco de la OMC. El proyecto incluía un cronograma de hasta quince años, con productos que podrían ser liberados en el año posterior, otros en cinco años y otros en diez años. Para el plazo máximo estarían reservados los productos más sensibles como azúcar y textiles (MRECIC, 2004). Al respecto, la prensa reflejaba: "Si este esquema no se respeta y EE.UU. no está dispuesto a negociar sus subsidios, la orden del gobierno de Néstor Kirchner es retrasar la apertura del mercado local y firmar en enero de 2005 una versión híbrida del ALCA" (La Nación, $2 / 2 / 2004)$. El diario destacaba las consultas directas al sector agrícola privado argentino para avanzar o no en las negociaciones:

El secretario de Relaciones Económicas Internacionales, Martín Redrado, llamó por teléfono al presidente de la Sociedad Rural Argentina, Luciano Miguens, y al presidente del Centro Azucarero Argentino, Jorge Zorreguieta, para saber hasta dónde podía tensar la cuerda. La reunión fracasó porque el Mercosur no acepta un ALCA con la agricultura postergada. (La Nación, 16/02/04)

A partir de allí las negociaciones quedarían estancadas, como sostenía el funcionario argentino, Gustavo Idígoras, por ese entonces director de Mercados Agroalimentarios de la Secretaría de Agricultura, de manera más protocolar que el centenario diario: "Es evidente que habrá un relajamiento de la negociación" ( $L a$ Nación, 16/2/04). A tal punto que, como también señalamos, las posteriores reuniones programadas para el mes de marzo y abril, como forma de continuar acercando las partes, fueron canceladas. El agro argentino no quería frenar el ALCA, pero no estaba dispuesto a poner en un segundo plano el tema de los subsidios pararancelarios. La relación entre gobierno argentino y corporaciones agropecuarias, en este aspecto, fue armoniosa y contrasta con el caso brasileño. 


\section{A MODO DE CIERRE}

En primer lugar, pudimos observar que tanto en Argentina como en Brasil el ALCA generó aceptación en las corporaciones agrarias. La idea de un acuerdo regional que liberara el comercio e incrementara las exportaciones de materias primas y de manufacturas de origen agropecuario fue algo deseado por las principales asociaciones del sector, como la SRA de Argentina y la CNA de Brasil.

Ahora bien, en segunda instancia observamos que las condiciones que impuso Estados Unidos en las negociaciones perjudicaban los intereses del sector agrarioexportador. Así es que en ambos países las principales representaciones corporativas agrarias demandaron a Estados Unidos una mayor voluntad para discutir el acceso a mercados y, al mismo tiempo, la eliminación de los subsidios internos paraarancelarios a sus productores, que resultaban distorsivos para avanzar en las negociaciones por la liberalización del comercio, tanto en el marco de la Ronda Doha como en el ALCA. La primera cuestión fue señalada con mayor énfasis por los productores rurales brasileños que, si bien rechazaban los subsidios paraarancelarios internos, entendieron que lo central de las negociaciones para avanzar en un acuerdo era la reducción tarifaria para la ampliación de nuevos mercados. Los argentinos hicieron mayor hincapié sobre los subsidios distorsivos y bregaron por enlazar las negociaciones de la OMC con las del ALCA. Esta es una de las principales diferencias encontradas entre los casos analizados.

En tercer lugar, desde el punto de vista de la estrategia negociadora, el posicionamiento de las asociaciones del agro argentinas tuvo como prioridad negociar desde el MERCOSUR, cuestión en la que hubo un rápido acuerdo con el gobierno. Los brasileños, por el contario, no hicieron mención a la necesidad de acudir al bloque regional, del que tenían una imagen muy negativa y sobre el que no pretendieron reclamar su uso para las negociaciones. Este es otro matiz entre las corporaciones agrarias de ambos países.

La relación entre corporaciones y gobiernos muestra también algunas divergencias. Mientras que en Argentina se construyó un entendimiento entre ambos, en Brasil hubo mayores tensiones, sobre todo desde la llegada de Lula al poder. En el primer caso, a pesar de amplias disidencias entre las corporaciones y el kirchnerismo durante los primeros meses de gobierno, por ejemplo sobre retenciones a las exportaciones, la política económica en general y temas como los derechos humanos, encontramos apoyo con respecto a la cuestión comercial y regional, específicamente en las negociaciones por el ALCA. En este sentido, el posicionamiento de los negociadores gubernamentales argentinos en los temas comerciales y agrarios fue bastante similar al que reclamaban las entidades patronales del sector agrario. En Brasil, con la llegada de Lula y los cambios en Itamaraty, comenzaron a generarse cortocircuitos justo cuando las instancias donde se discutía el ALCA evidenciaban desacuerdos; situación que contrasta con el segundo mandato de Cardoso donde se registró una mayor interacción entre empresarios y gobierno. Las fuertes objeciones de los empresarios del agronegocio al gobierno de Lula fueron en torno a la ideologización y politización desplegada por Itamaraty sobre el proyecto ALCA que, desde la mirada de ellos, contribuyó a desplegar una imagen negativa del proyecto a escala regional.

Si bien las objeciones al ALCA por parte de las corporaciones y asociaciones empresarias del agronegocio de ambos países no se debieron a cuestionamientos ideológicos y políticos al proyecto, ni desembocaron en una impugnación total del mismo, confluyeron con la acción gubernamental de cuestionar los plazos, alcances y también algunos de los principios de la iniciativa norteamericana entre los años 2003 y 2005. También, sin buscarlo, las objeciones de las patronales agrarias confluyeron con la protesta social y la resistencia en las calles contra el ALCA. Aunque las corporaciones deseaban y buscaban el acuerdo, sus cuestionamientos a la particular forma de libre comercio propuesta por Estados Unidos para la región fueron vitales para trabar el avance de las negociaciones más generales. Sin buscarlo deliberadamente, las corporaciones agrarias cumplieron un rol importante en el cuestionamiento al ALCA que terminó posteriormente en el contundente rechazo en la Cumbre de las Américas de Mar del Plata de noviembre de 2005. Tener en cuenta los intereses de estos sectores en estos países es importante para entablar nuevas 
negociaciones como las que se desplegaron en la coyuntura reciente. El peso que tienen para inferir ante los gobiernos y en las negociaciones no debe soslayarse, tanto para avanzar en un acuerdo como para objetarlo, según sus intereses puestos en juego.

\section{Fuentes y Documentos}

CEB (1999): "Documento para el III Foro Empresarial de las Américas"

CNA (2002): "Presentación para el VII Foro Empresarial de las Américas "Editorial" (enero-febrero de 2002), Revista Gleba.

"El ALCA, una oportunidad de oro" (7 de octubre de 2002), Valor Económico.

"El azúcar y los subsidios: otro caso similar a lo acontecido en el MERCOSUR" (enero-febrero de 2003), Revista Gleba.

"El lugar de Brasil en las negociaciones comerciales" (24 de marzo de 2003), Gazeta Mercantil.

"El palco oficial, con un tono de calculada austeridad" (3 de agosto de 2003), Clarín.

"Falta de voluntad política de Itamaraty en las negociaciones por el ALCA" (octubre-noviembre de 2003), Revista Gleba.

"La CNA e Itamaraty diseñan una acción conjunta contra los subsidios" (3 de mayo de 2002), O Estado do Sao Paulo.

"La cumbre de Miami terminó suscribiendo un ALCA acotado" (21 de noviembre de 2003), Infobae.

"La nueva ley agrícola norteamericana y el proteccionismo de los países centrales" (septiembre de 2002), Revista Gleba.

"La SRB y las negociaciones por el ALCA" (5 de abril de 2004), Valor Económico.

"La versión light para la liberalización del comercio parece tranquilizar a promotores y detractores y se modera la batalla por el ALCA" (23 de noviembre de 2003), La Nación.

"Las negociaciones de Puebla por el área de libre comercio" (enero-febrero de 2004). Revista Gleba.

"Las negociones por el ALCA: declaraciones de Furlan" (7 de octubre de 2002), Gazeta Mercantil.

"Los componentes ideológicos en las negociaciones comerciales"(11 de abril de 2004), O Estado de Sao Paulo.

"Los empresarios piden negociar el ALCA desde el MERCOSUR" (17 de noviembre de 2003),El Cronista Comercial.

"Los subsidios distorsivos en Estados Unidos y sus implicancias para las negociaciones por el ALCA" (abrilmayo de 2001), Revista Gleba.

MRECIC (2004): "Sólo dos visiones del ALCA conviven en Puebla”. Recuperado de (http://www.mreci c.gov.ar/solo-dos-visiones-del-alca-conviven-en-puebla). "Peleas en el gabinete de Lula por las negociaciones del ALCA" (8 de octubre de 2003), Clarín.

"Piden que el agro no sea moneda de cambio en OMC" (11 de agosto de 2003), Ámbito Financiero.

"Priorizar el acceso a los mercados" (mayo-junio 2003), Revista Gleba.

"Solá: en la Ronda del GATT se define el futuro agrícola" (12 de julio de 1990), La Nación.

SRA (2003): "ALCA: sin el agro no hay negociación posible"

"Un acuerdo donde todo pueda negociarse" (octubre de 2001), Revista Gleba.

\section{ReFERENCIAS}

Botto, M. y Tussie, D. (2003). El ALCA y las cumbres de las Américas ¿una relación público privada? Buenos Aires: Biblos / FLACSO.

Gudynas, E. (2005). El 'regionalismo abierto' de la CEPAL: insuficiente y confuso. En Observatorio Hemisférico, International Relations Center. Recuperado de http://www.cipamericas.org/es/archives/1324 
Estay J. y Sánchez Daza G. (2005). El Alca y sus peligros para América Latina. Buenos Aires: CLACSO.

Junqueira Botelho, A. J. (2003). La sociedad civil en el proceso de integración comercial: el caso brasileño. En Botto M. y Tussie D. (Editoras), El ALCA y las cumbres de las Américas ¿̇una relación público privada? (pp. 171-192). Buenos Aires: Biblos / FLACSO.

Katz, C. (2006). El Rediseño de América Latina, ALCA, MERCOSUR y ALBA. Buenos Aires: Ed. Luxemburg.

Kan, J. (2009). Vuelta previa al 2001. La devaluación del Real de 1999 y su impacto en la burguesía argentina. En Bonnet A. y Piva A. (Editores), Argentina en pedazos. Luchas sociales y conflictos interburgueses en la crisis de la convertibilidad (pp. 223-251). Buenos Aires: Ed. Continente / Peña Lillo.

Kan, J. (2010). De Cancún a Mar del Plata. Las disputas y alineamientos entre los gobiernos de la región y Estados Unidos ante la derrota del ALCA. Ciclos de la historia, la economía y la sociedad, 19(37-38), 77-102.

Kan, J. (2015). La integración desde arriba. Los empresarios argentinos frente al MERCOSUR y el ALCA. Buenos Aires: CICCUS-Imago Mundi.

Kan, J. y Pascual R. (2011). La política exterior argentina post 19 y 20 de diciembre. Revista Herramienta, 46, 97-107. Recuperado de http://www.herramienta.com.ar/revista-herramienta-n-46/la-politica-exterior-argentina-post19-y-20-de-diciembre

Lattuada, M. (2003). Acción colectiva y corporaciones agrarias en la Argentina. Transformaciones institucionales a fines del siglo XX. Bernal: Universidad Nacional de Quilmes.

López, A. y Porta, F. (1995). Nuevas modalidades de inserción internacional: El MERCOSUR. En Kosacoff, B. (Ed.), Hacia una nueva estrategia exportadora. La experiencia argentina, el marco regional y las reglas multilaterales (pp. 231-278). Bernal: Universidad Nacional de Quilmes.

Morgenfeld, L. (2006). El ALCA, ¿̇a quién le interesa? Buenos Aires: Ediciones Cooperativas.

Morgenfeld, L. (2011). Vecinos en Conflictos. Argentina y Estados Unidos en las Conferencias Panamericanas (1880-1955). Buenos Aires: Ed. Continente / Peña Lillo.

Rapoport, M. (2008). Argentina y el MERCOSUR: ¿Dilema o solución? CICLOS en la historia, la economía y la sociedad, 17(33-34), 3-18.

Salvia, S. (2014). Asociaciones empresarias del agro y crisis de acumulación, 1998-1999. Un antecedente de la mesa de enlace. Mundo Agrario, 15(28).

Santana, R. P. (2000). “Area de Livre Comercio das Américas (ALCA): determinantes domésticos e política externa brasileira. Dissertacao Maestrado em Relacones Internacionais. Pontificia Universidade Católica. Rio de Janeiro.

Seoane, J. y Taddei, E. (2003). Movimientos sociales, conflicto y cambios políticos en América Latina. En OSAL, N ${ }^{\circ}$ 9. Buenos Aires: CLACSO.

Veiga da Motta, P. (2002). Trade Policy-Making in Brazil: Transition Paths. Institute for de integration of Latin America and the Caribbean, Papper 13.

\section{Notas}

1 Las traducciones del portugués al castellano de los diarios brasileños y de los documentos de las asociaciones empresarias brasileñas son propias.

2 Por ejemplo el MERCOSUR, en su primera etapa, privilegió la desgravación arancelaria entre sus socios en un plazo más corto que el estipulado originalmente, alentó la llegada de inversiones y dejó de lado la coordinación sectorial de algunas áreas de la economía afectadas por diferentes grados de competitividad entre Argentina y Brasil.

3 Luego de los reveses de Estados Unidos en la OMC de Cancún y de su pérdida de terreno en Miami ante los países del MERCOSUR en las negociaciones por el ALCA, la Cumbre de Monterrey se polarizó entre las duras posturas de Bush para afirmar el libre comercio en la región y los posicionamientos de Chávez condenando la política norteamericana. Como observó Kan (2010), sin negociaciones concretas, esta Cumbre tuvo resultados negativos para la relación de Estados Unidos con la región y para las negociaciones por el ALCA

4 Los FEA fueron instancias formales creadas por el ALCA que convocaban a los empresarios de la región a opinar y discutir las implicancias de la iniciativa. Tenían carácter consultivo y no resolutivo, es decir, no fueron instancias de negociación. 
5 Creada en la década de 1960 en reemplazo de su antecesora, la Confederación Rural Brasileña (CRB), continuó con el espíritu de centralizar la representación corporativa del sector, en el marco de las reformas introducidas por Vargas en la organización sindical y corporativa en la década de 1940. La CNA conforma un sistema sindical rural a nivel nacional que integra 27 federaciones, 2300 sindicatos rurales y alrededor de un millón y medio de productores asociados en forma directa. Agrupa a productores de diversos cultivos y regiones y de variadas extensiones de tierra. Aquellos con capacidad exportadora y cierta competitividad alentaron el uso de la entidad para acercar a las negociaciones por el ALCA.

6 Por ese entonces Furlan era directivo del grupo agroindustrial Sadía, del que también era miembro de la familia fundadora. En 2003 asumió como ministro de Desarrollo, Industria y Comercio Exterior del primer gobierno de Luiz Ignacio Lula Da Silva.

7 Algunas de las críticas de Miguens al gobierno fueron las siguientes: “El presidente de la Sociedad Rural (...) reclamó ayer una 'reforma profunda' del sistema tributario y cargó contra las retenciones a las exportaciones, que pidió reducir para que el campo 'recupere competitividad'. También insistió con la necesidad de 'reducir las retenciones' que gravan a las exportaciones del sector, pues según ejemplificó: 'de cuatro barcos con soja que exportamos, el Estado se queda con uno’. No se puede pedir reducción de subsidios a los demás países cuando acá se mantienen las retenciones’, enfatizó (...). El titular de la Sociedad Rural subrayó además que 'ningún plan económico tendrá éxito sin seguridad jurídica, con emisión descontrolada y sin medidas de fondo que permitan un crecimiento sostenido de la economía'. A su criterio, 'es indispensable que el Estado alivie los bolsones de pobreza de los cordones suburbanos', ya que 'no podemos aceptar que haya hambre en un país que produce alimentos para 300 millones de personas"” ("El palco oficial, con un tono de calculada austeridad...”, 2003). Con respecto a los derechos humanos, se posicionaron en contra de las primeras medidas del gobierno: "Miguens cuestionó elípticamente la posibilidad de derogar las leyes de Punto Final y Obediencia Debida, para que sean juzgados en el país un grupo de militares vinculados con la represión ilegal durante la última dictadura militar. 'No hay que mirar el pasado, sino apostar al futuro" ("El palco oficial, con un tono de calculada austeridad...", 2003).

\section{INFORMACIÓN ADICIONAL}

Este trabajo se encuentra en el marco de la investigación "Historia reciente de la integración latinoamericana. Los actores sociales ante la reconfiguración política regional en Argentina y Brasil durante la década de 2000": que es parte de mi proyecto de Posdoctorado en Ciencias Humanas y Sociales de la Facultad de Filosofía y Letras de la Universidad de Buenos Aires (Resol. n 3785 ). 